\title{
A study on the construction of a disaster situation management system in Korea based on government 3.0 directive
}

\author{
Y. J. Park, I. K. Jeong, J. W. Seo \& J. Y. Kim \\ National Disaster Management Institute, Korea
}

\begin{abstract}
Korea has gradually increased the importance of effective disaster management while experiencing a large scale disaster accident. Existing constructed disaster management systems in Korea have operated their own system for each institution and for the difficulty in figuring out various disaster information at a glance so that it is limited to the management of a rapid disaster situation. Korea has presented the new paradigm of disaster management 3.0 based on open, sharing, communication, collaboration to suit the flow government 3.0 throughout information cooperation, related organization and communication with the public. As a result, it has developed a smart big board (SBB) which is a new disaster management system grasping the real time disaster situation by integrating the scattered information. This system can grasp a real time disaster situation based on a map to display the scattered information such as sensor, satellite, GIS and SNS data. This study introduces a smart big board and shows how the utilization of a smart big board through a field-based and expert analysis of disaster type, customizable functionality. Smart big board can make decisions in a real time disaster situation and quickly handle it by disseminating and analysing information in real time.
\end{abstract}

Keywords: smart big board, disaster management system, government 3.0, real time.

\section{Introduction}

Korea is a region where many disasters occurred on the characteristics of the climate and terrain. The Korea has experienced the human and material damage by heavy rainfall and typhoons that occur every year. Recently, disaster 
diversified its type caused by industrialization and urbanization and is difficult to predict by generating in a complex manner. After experiencing a large disaster in Korea such as Mt. Umyeon landslide, Mauna resort collapse, Sewol-ho ferry sinking, the importance of construction a national level of integrated disaster management system is increasing ( $\operatorname{Lim}[1])$.

Existing disaster management system was operated by being classified according to necessary function and role for each institution. As a result, when disaster occurs, it is not possible to grasp integrated disaster information and spent a lot of time to the corresponding consultation between institutes. Since then, The Ministry of Public Safety and Security which integrated disaster \& safety function distributed each institute such as marine, fire, safety is established and plays the role of disaster control tower as a national disaster and safety comprehensive institute.

In the foreign country, it is operated the advanced disaster management project using ICT such as Mobile, social media, big data and GIS. The United States provides disaster warning SMS with mobile subscribers in the region which is affected by the disaster using PLAN (Personal Localized Alerting Network). Also, The Australian Government was carried out disaster management project after Victoria conflagration was occurred using social media by the need of public-officer cooperative relationship and real-time information. As a result, the Korea was aware of the problems of existing disaster management system and then it is necessary to construction an efficient and integrated disaster situation management system and is possible to manage realtime disaster situation (Han and Seo [2]).

In this paper introduces smart big board which is smart disaster management system grasping the real time disaster situation by integrating the scattered information (Weather, CCTV, and SNS etc.) and shows case of applying SBB about disaster occurred in every season.

\section{Smart big board}

\subsection{New paradigm, disaster management 3.0}

Government 3.0 in Korea is a new government operating paradigm providing public-customized service by opening and sharing public-information and communication and collaboration without a partition between institutes (MOSPA [3], Park and Park [4]). For now, disaster management 3.0 is changing from out of the disaster management of government led to the core value of 'open', 'sharing', 'communication', 'collaboration'. Especially, the collection of disaster information using ICT can increase their value by generating information with the public as a human sensor and it is meaningful to be providing customized information with the user. Therefore, a disaster management system based on disaster management 3.0 will ensure the public safety and life to support effective and integrated decision-making by creating disaster information of high value. 


\subsection{Characteristics of smart big board}

\subsubsection{Concept}

Smart big board constructed in the beginning of disaster management is a term that combines smart technology and big data and a web-based system which supports the monitoring and accurate disaster response of decision-making of an effective disaster situation by the expression analysis on one of the maps integrating the scattered information. Thus, a disaster situation management system is changed as follows (table 1).

Table 1: Change of disaster situation management system.

\begin{tabular}{|c|c|c|}
\hline $\begin{array}{c}\text { Information } \\
\text { type }\end{array}$ & $\begin{array}{c}\text { As is } \\
\text { institute (construction DB) }\end{array}$ & $\begin{array}{c}\text { To be } \\
\text { Integration of cooperation } \\
\text { information (ICT) }\end{array}$ \\
\hline $\begin{array}{c}\text { Information } \\
\text { analysis }\end{array}$ & Experiential judgment & $\begin{array}{c}\text { Scientific analysis such as } \\
\text { simulation }\end{array}$ \\
\hline $\begin{array}{c}\text { Field } \\
\text { information }\end{array}$ & $\begin{array}{c}\text { Media information such as } \\
\text { TV, news }\end{array}$ & $\begin{array}{c}\text { Advanced technologies } \\
\text { such as SNS, MMS,UAV }\end{array}$ \\
\hline $\begin{array}{c}\text { Display } \\
\text { method }\end{array}$ & Paper & GIS map \\
\hline $\begin{array}{c}\text { Cooperative } \\
\text { relationship }\end{array}$ & One-way & $\begin{array}{c}\text { Cooperative relationship } \\
\text { (government - public and } \\
\text { central - local) }\end{array}$ \\
\hline $\begin{array}{c}\text { Dangerous } \\
\text { warning }\end{array}$ & Media information & Regional custom \\
\hline
\end{tabular}

Starting development in May 2013 up to January 2015, the secondary version is at the state of being released. The greatest feature of this system is a cooperation and sharing of information between institutes. It displays necessary information a minimum of DB scale and timely by relating open API maintaining a cooperative relationship of private agencies together. It provides weather information (temperature, wind, and precipitation), satellite, radar image, CCTV, SNS which needs disaster management as the basic information.

It usually operates monitoring based on the collected information and can prevent locally high region disaster damage from focused monitoring during heavy rain and snow. If the disaster occurs, smart big board can first check the disaster status using CCTV and SNS of field citizen around the disaster. Also, Decision personnel can be performed by grasping the state of the overall scene in the room through smart big board by collecting field information via a mobile app that has been distributed to the field personnel (fig. 1).

Moreover, it supports the optimal situation judgment combine related information and NDMI technology to assist scientific decision. Recently, in order to analyse the needs of disaster situation management system, it has maintained organic cooperative relationship between the central and the local governments to test operate selected the three bases local government. 


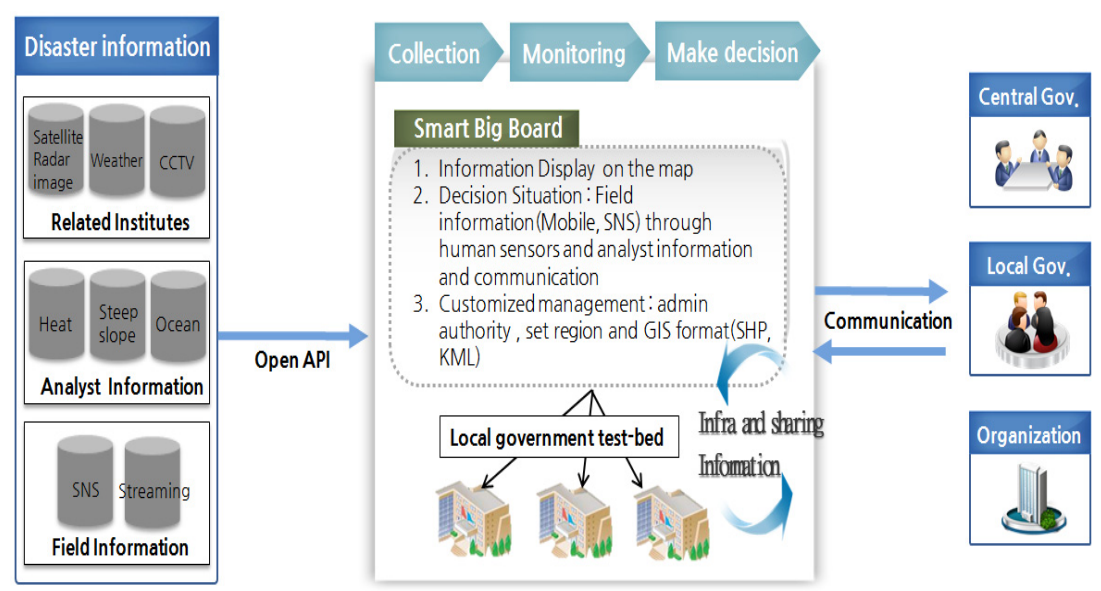

Figure 1: Smart big board process.

The following are the main screens of smart big board (fig. 2). On the map radar image, nationwide SNS information and the alarm pop-up areas where the wind blows appear. On the left, it is possible to select the layer of disaster information; the right part is displayed weather analysis information. Danger/alert/care color depending on the weather information is divided into the screen so that can intuitively grasp a dangerous situation.

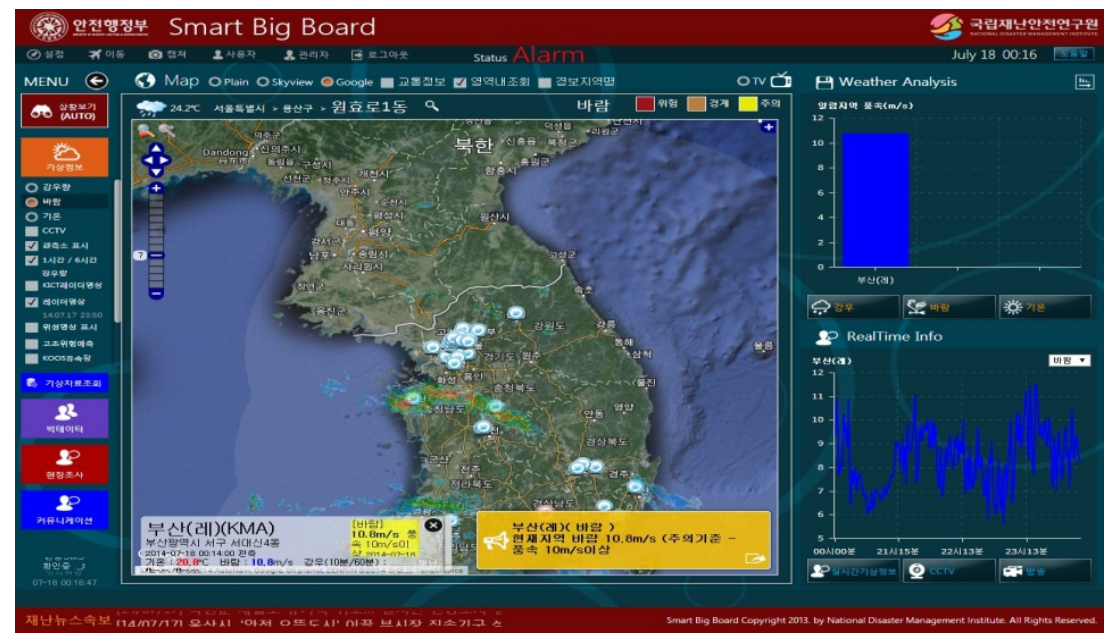

Figure 2: System main page.

\subsubsection{Main function}

Smart big board supports five functionally disaster situation management. Field information sharing and a sign of disaster detection is the main function (as shown in table 2). 
Table 2: Main function.

\begin{tabular}{|c|c|}
\hline Function & Detailed \\
\hline $\begin{array}{c}\text { Field } \\
\text { investigation }\end{array}$ & $\begin{array}{l}\text { - Location, GPS tracking } \\
\text { - Web-display video streaming } \\
\text { (video, picture, SMS) }\end{array}$ \\
\hline Communication & $\begin{array}{l}\text { - SMS chat and video call }(1: 1) \\
\text { - Alert and send message to people } \\
\text { - send and receive message box }\end{array}$ \\
\hline Big data analysis & $\begin{array}{l}\text { - search of hot issue trend } \\
\text { - regional keyword analysis } \\
\text { - download disaster twitter }\end{array}$ \\
\hline $\begin{array}{l}\text { Disaster analysis } \\
\text { (NDMI system) }\end{array}$ & $\begin{array}{l}\text { - danger alert of steep-slope collapse } \\
\text { - prediction information of high-tide } \\
\text { - estimated flooding inundation map } \\
\text { - tweet frequency distribution map }\end{array}$ \\
\hline Customizing & $\begin{array}{l}\text { - display attribute KML file } \\
\text { - display GIS format(SHP) } \\
\text { - Setting alerts attract area (weather, SNS etc.) }\end{array}$ \\
\hline
\end{tabular}

\subsection{Application of seasonal}

Smart big board supports preparedness-response works of disaster planning's supports and the rapid and comprehensive decision-making. Disaster that can lead to personal injury by classifying according to the season and we tried to apply to seasonal case of the disaster situation management using smart big board.

\subsubsection{Spring: forest fires}

The case of Pohang forest fires (March 9th, 2013) gave 79ha forest, assuming such a situation, we applied to smart big board. When a large-scale fire occurred, smart big board is transmitted field video using 1:1 chat function of smart big board central-government and it is determined weather air assist, damage support (as shown in fig. 3).

Therefore it is possible to support disaster response jointly to maintain organic cooperative relationship of central-local government.

\subsubsection{Summer: heavy rainfall}

Summer of Korea is gradually localized concentrated rainfall; it is when rainfall is concentrated changing the difficult type predictive. So it is necessary to manage the real-time disaster situation by region. The heavy rainfall region was monitored through the 1 hour/6 hour cumulative rainfall and radar image. When looking at the situation of heavy rainfall June 18th, 2014 15:50 AM back and forth, in spite of the not so far region, it is possible to confirm that the rainfall is difference more $40 \mathrm{~mm} / \mathrm{hr}$. (as shown in fig. 4). Also, it can be determine the safety situation of detailed regions through SNS, CCTV in the region. 


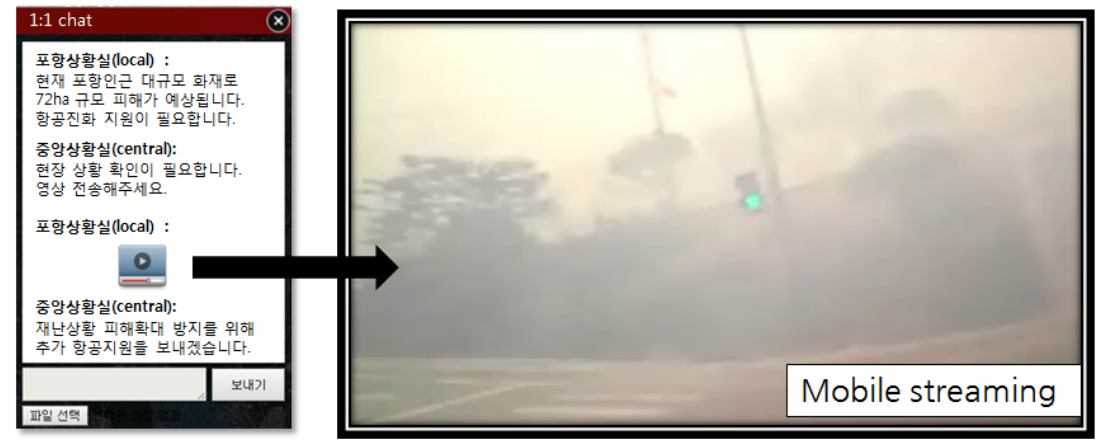

Figure 3: Example of application forest fires.

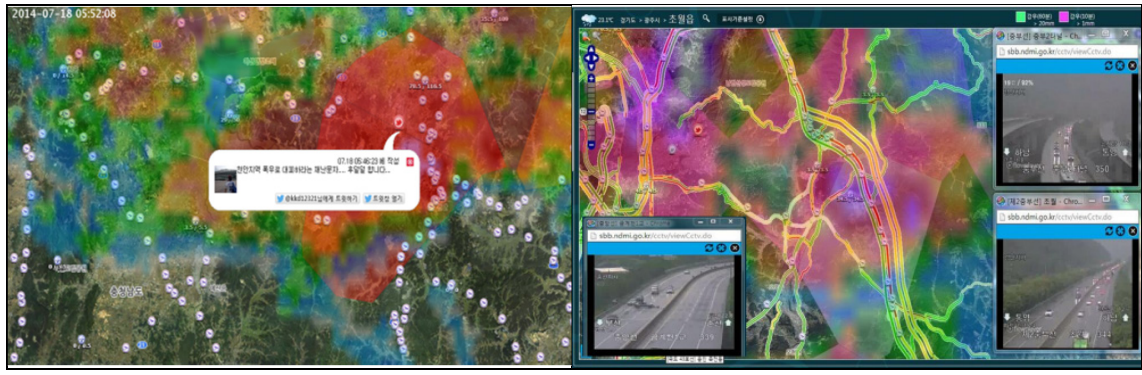

Figure 4: Example of application heavy rainfall.

\subsubsection{Fall: typhoon}

As Nakri typhoon (No.12) that occurred August 2th, 2014 move north in Korea, the region of influence range of rainfall and wind can be confirmed that SNS tweet increases. Tsunami prediction information analysed by the expert can determine the tsunami expected area by registering KML file in smart big board.

Because the size of typhoon scale is not large, Nakri tsunami in Korea can be seen that the effect is not high as shown on the right (fig. 5).

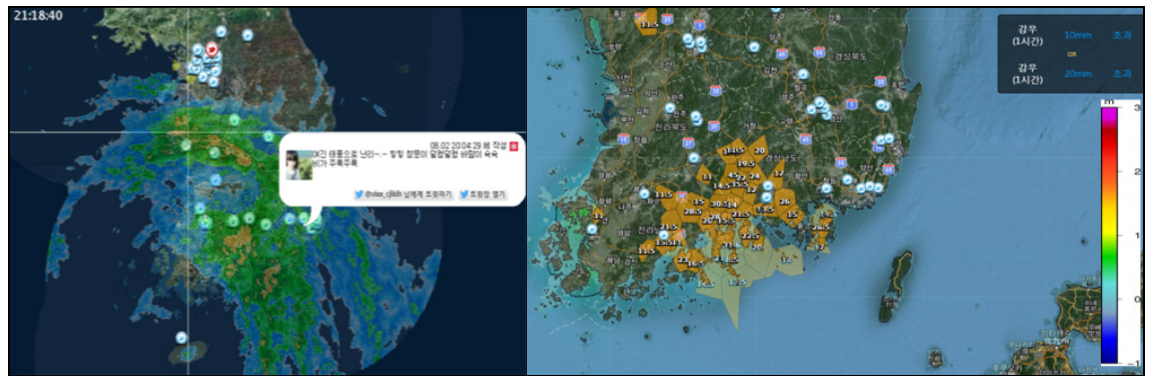

Figure 5: Example of application typhoon. 


\subsubsection{Winter: heavy snow}

Due to heavy snow on December 1st, 2014 information regarding keyword 'Snow' of SNS increased and regions of less than $-3^{\circ} \mathrm{C}$ were marked on the map as yellow polygon and then it can be seen that their regions will increase over time (as shown in fig. 6). To prevent damage caused by the heavy snow and cold, Chungnam Hongseong country from early morning was field monitoring streaming video delivered though snowplow and disaster administrator can be relayed the field through smart big board.

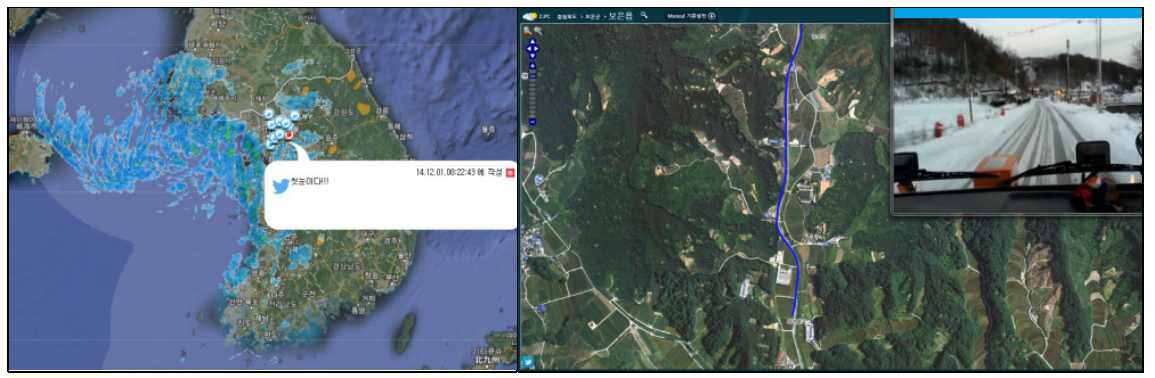

Figure 6: Example of monitoring heavy snow.

\section{Conclusion}

In Korea is urgently required time the construction of integrated national level disaster management to increase large scale disaster accident. In this paper introduces SBB and shows case of applying SBB by focusing two kinds of changes to technology development such as government 3.0 promotions and ICT, Mobile.

The conclusions of this study are shown below.

First, smart big board is determined to be rapid initial handle based on realtime sharing, analysis, dissemination as link various equipment for collection of field information and cooperate disaster information to destroy the wall between institute. Furthermore, Utilization of UAV in inaccessible region with people is expected to be to grasp the real-time on field information.

Second, when we apply smart big board in season disaster situation, it is possible to decide not only monitoring but also disaster situation make-decision using a variety of function.

In the future, we are going to study about operating technology as open platform for operating of common disaster situation management system, disaster element technology and cooperative standardization.

\section{References}

[1] Lim, S.K., Conceptual Inquiry and Policy Challenges on Disaster Management 3.0, Korean Society of Hazard Mitigation, 14(4), pp. 213-222. 
[2] Han, Y.M. \& Seo, H.B., Analysis of disaster response advanced cases of smart ages using mobile and social media, National Information Society Agency, pp. 5-19, 2011.

[3] Ministry of Security and Public Administration, Government 3.0 white paper, MOSPA, pp. 4-6, 2013.

[4] Park, G.S. \& Park, H.S., Pre-emptive military-civilian conflict management system for the realization of government 3.0, Korean Review of Crisis \& Emergency Management, 10(1), pp. 139-162. 